\title{
Learning Innovative Maternal Instinct: Activity Designing Semantic Factors of Alcohol Modification in Rural Communities of Thailand
}

\author{
Pitipong Yodmongkol ${ }^{1}$, Thunyaporn Jaimung ${ }^{1}$, Nopasit Chakpitak ${ }^{1} \&$ Pradorn Sureephong $^{1}$ \\ ${ }^{1}$ College of Arts, Media and Technology, Chiang Mai University, Chiang Mai, Thailand \\ Correspondence: Thunyaporn Jaimung, College of Arts, Media and Technology, Chiang Mai University, Chiang \\ Mai, Thailand. Tel: 66-857-242-522. E-mail: th18th18@hotmail.com
}

\author{
Received: April 30, 2014 Accepted: June 11, 2014 Online Published: July 27, 2014 \\ doi:10.5539/ies.v7n8p44 URL: http://dx.doi.org/10.5539/ies.v7n8p44
}

\begin{abstract}
At present, Thailand is confronting a serious problem of alcohol drinking behavior which needs to be solved urgently. This research aimed to identify the semantic factors on alcohol drinking behavior and to use maternal instinct driving for housewives as village health volunteers in rural communities, Thailand. Two methods were implemented as the problematic classification and the semantic factors model among thirty housewives being as village health volunteers. The findings revealed two aspects: health and children's cognitions had the maximum percentage. Most of them were related to the method of social skills, being a role model in families and communities and the designing activities implemented which led to the prominent caretaking characteristics relating to the life skills. Furthermore, this study can expand the idea and new alternative to the rural communities which might face with the same trouble arising from the alcohol drinking behavior.
\end{abstract}

Keywords: alcohol drinking behavior, alcohol modification, maternal instinct, attention, semantic factor, knowledge management in behavior, learning

\section{Introduction}

Thai usually earns their living by doing agriculture without any technology like the other industries, therefore, they mostly face with the problems of unemployment, low income, non-educated knowledge, early marriage as well as high stress (Muntaner et al., 2010). Moreover, they have to encounter with the poverty because of alcohol drinking behavior. So, the aims of this study are to identify and apply the semantic factors based on maternal instinct for housewives as village health volunteers in rural communities. They also have their own ways to eliminate these problems, especially stress, by drinking alcohol (Thamarangsri, 2006). As a result, alcohol drinking becomes a major problem found in the village or community since they work and live so close in the rural communities and this problem also leads to the problems like the impact of the loss of health, economy and society. As global burden, alcohol consumed affects 3-8\% deaths and 4-6\% disability-adjusted life-years. As the event in Europe, alcohol consumption caused 1 in 7 men and 1 in 13 women burden of deaths. Global loss of cost from alcohol consumption was estimated at about $1 \%$ of the gross national product (Rehm et al., 2013). This number is comparable to the total Gross Domestic Product of 1.99\% in Thailand in 2010. The studies also revealed that Thailand was ranked 1 in 3 of top alcohol consumption in Asia. The loss of Thailand was estimated at about 156,504 million Baht. Therefore, the burden and the increased costs should be reduced as the known effects (Thavorncharoensap et al., 2010). Nowadays, the number of women who drink alcohol has increased tremendously. Although they have the maternal instinct, they cannot save their family from the effects of drinking alcohol behavior in Thailand, especially rural communities. Interestingly, several studies found that alcohol consumption in women drinkers is increasing and the gap of gender is narrower (Smith and Foxcroft, 2009). The women have more opportunities to gather in society and alcohol drinking behavior. However, when women have pregnancy, they can quit or decrease in alcohol drinking behavior as they fear the effects of alcohol drinking on fetuses. This behavior is related with naturalness and warmth on female traits. This trait is found in most of women undergoing maternal instinct (Ruddick, 1989). It is very powerful and is driven since the mothers are eager to do everything for their children and families. Even though maternal instinct is significant for the welfare of children (Duflo \& Urdy, 2004), women pattern of alcohol consumption still tends to increase dramatically (Valentine et al., 2010) as well as the studies in Thailand indicated that imitated behavior influences on social learning in rural communities and alcohol drinking behavior could be increased by social activity. The 
villagers have the belief on the positive effect from alcohol drinking behavior such as relaxation, reckless courage, spree, extrinsic and etc. For example, local government and employers usually pay wages for their workers by alcohol drink. Then, employees satisfy with this pleasure and it will be easy to close to the workers. Significantly, many villagers own their stalls for selling alcohol because they are able to earn more income and invest with low cost; local manufacturing. Due to the high degree of alcohol and inexpensive price, rice-whisky is popular alcohol drink. Besides, the participation of villagers is the main factor with alcohol for succeeding in the community. Moreover, Alcohol is as the tool bounding relationship. Alcohol is the legal addiction; therefore, it is difficult to control. The women workers in rural communities have the increase of taste in alcohol drinking behavior, especially after daily work. It is caused by husband's and friends' invitation, including alcohol drinking behavior of family members. Sometimes, they have stress. Additionally, social contact happens to be joyful in getting together and singing karaoke. These are all associated with alcohol consumption in women workers (Buathong, 2005). It is widely known that mothers' behavior affects children, but children still are neglected by social learning, especially in families. It is possible maternal instinct cannot drive in mothers on alcohol drinking behavior. However, the previous study focused more on model, creating based on maternal instinct on alcohol drinking behavior. After that the effectiveness of the model should be improved and maternal instinct should be driven in mothers on alcohol drinking behavior. Therefore, Thailand needs the urgent solution of alcohol drinking behavior by applying the theory of maternal instinct driving. Moreover, it is beneficial not only the members of the families but also to the communities. As the evidence mentioned, this study was applied by using semantic factors model based on maternal instinct to design activities to prove whether the model could be practical. Reasonably, the study aimed to identify and implement semantic factors based on maternal instinct for housewives as village health volunteers. In addition, this model can assist in designing activities in training on alcohol drinking behavior which can help the village health volunteers manage the problems caused from the impact of alcohol drinking behavior on the communities. Then, they can apply the process of analogy and the authentic situation in the context of rural communities. Lastly, it will be evaluated based on maternal instinct deriving from alcohol drinking behavior of health volunteers being as housewives. The conclusion of this study might be an alternative to help the public officer manage for an alcohol solution in the rural communities.

\section{Previous Research}

Before designing research methodology will be presented in the next step, this section will clarify the elements of research development. We should understand about what the problems and the methods of alcohol drinking behavior, "why we use maternal instinct driving and how to design semantic factors and activities by attention." We could follow in this literature review.

\subsection{Alcohol Drinking Behavior Modification}

Alcohol drinking behavior modification was studied by many researchers with the aims of two cognitive constructions such as alcohol expectancy and drinking refusal self-efficacy in order to make understanding of alcohol use and abuse. It is the effective quantity of alcohol consumption (Oei \& Burrow, 2000). This behavior creates the complex result and displays on cognitive, behavioral, coping strategies, alcohol expectancies and motives of drinking. They could be designed the cognitive model of drinking. The result of the model probably reveals the positive feedback which increases the confidence and tension reduction. As the negative of effects are drinking motive and avoidant coping, the alcohol drinking behavior is initiated from the cognition of alcohol consumers. Also, social norm drinking and social motive on alcohol consumption affect alcohol drinking behavior, social norm drinking has descriptive norm (individual's perceived prevalence of alcohol consumption) and injunction norm (individual's perceived approval of drinking by their peer, social distal peers, social close peers). They are the key predictors of alcohol drinking behavior as well as cognitive behavior therapy is significant for alcohol drinking behavior. Eberl et al. (2013) studied CBM (Cognitive behavior modification) and found that the intervention of CBM could change the maladaptive and neurocognitive processes in alcohol-dependent patients (alcohol addiction). They took the alcohol avoidance training course (refusal behavior). They were less relapsed at 1 year than the other patients. As the group of case study focuses on the treatment in adult with alcohol dependence, Mowbray et al. (2013) found that the key success of mechanism of alcohol modification was drinking goal setting and desired abstinence of person. They could understand the benefits and risks of alcohol drinking behavior because these two issues are useful for the clinician to design the intervention and motivate in the alcohol-dependent patients (alcohol addiction). Therefore, we could pick up and apply the guideline of this alcohol modification such as the cognition and behavior of the drinkers. It led to understand the components as being goal setting together. 


\subsection{Maternal Instinct Driving}

In many developing countries, it is found that women are the key driver to care for their families (Yunus \& Jolis, 2007). Similarly, the study indicated that almost of the primary caregivers are women and mothers. They work effectively in health promotion for social action. It can be empowered by five methods: (1) motivation for action, (2) empowerment support, (3) initial individual action, (4) empowerment program and (5) institutionalization and replication (Kar et al., 1999). Additionally, the study of Kawachi et al. (1999) revealed that the experience of women influences the potential of mortality and morbidity in health promotion such as increasing of neonatal survival is high-mortality setting in developed countries. As health and well-being depend on participation in learning and action meeting with government community health workers, self-help group in organizations and experiences associated with space and time with women. Expectedly, the women had the power of decision-making (Nair et al., 2012). It affects to diminish barriers to health services, quality of caring, provisioning safe places for social interaction, strengthening people's sense of belonging to a particular community, empowering on community's health. However, housewives and working mothers who take the responsibilities for health care might be in the poor family because of less education, lack of employment and financial difficulties (Rostad et al., 2006). For example, the mothers have more bargaining power which their children will have the best nutrition in rural community as well as social and marital factor of them in urban influences women's health by the events. The social factor supports resources and access of social network and social power and the marital factor is polygenic and illness. All of events, the women are the power and have a potential. If they have the opportunity, they could be responsible in the honesty and crossed the dilemma problems.

\subsection{Attention}

Underlying maternal instinct driving, the cognitive capacity was driven by attention. It is called attentive love or loving attention. The tasks go on all the time and everyday opportunity as cumulative results. They are knowledge of individual and knit of maternal thinking. Their action could be referred to the pain, desire and project through the child's well-being goal. This opportunity will be related between mothers and children. It is a discipline for loving and attachment. Maternal attention would be aroused by the responsibility to inform actions. It led to the training of maternal work and could derive to the patients and others since the cognitive of mother could empathy capacity, which was extracted from the mother experiences (Ruddick, 1989). Similarly, Strenberg (2009) studied the characteristic of attention which was an automatic process. It consists of : (1) Concealing from consciousness, (2) Unintentional and (3) They consume few attention resources. They have three roles, for example, it is useful for monitoring their interactions of the environment, it could link the past memories and present to deliver the sense of continuous experience and it could control and plan the future actions. However, the other research studies, for example, Beebe et al. (2010) represented the results of attention learning from chronic sleep restriction in adolescents and grade five students (Liu et al., 2012), and showed the attention to the comprehension test and learning efficiency. Therefore, the attention was used in the various studies, but it has never represented on alcohol drinking behavior modification. In this study, we are interested in maintaining the attention in maternal instinct and creating the explicit knowledge for health workers in learning.

\subsection{Semantic/Semantic Factors Designing/Activity Design}

The behavior could be learned by the sensation channels of human. They are verbal and nonverbal through as well as an effect on the memory of the brain. The brain has increased ability to record which easy to memory by similar words, since it could relate word for word by the semantics. The semantic could be defined as the study in the various fields such as psychology, linguistics, cognitive science and artificial intelligence (Pirro, 2009), for example, psychology; the semantic structure of category generally studies in the patients such as schizophrenia, dementia and Alzheimer patients etc. For schizophrenia people which were researched by Sumiyoshi et al. (2001), they found the deficit of semantic structure of them commonly. They will degrade the cultural background and verbal intelligence. The testing of the maternal was changed, so it is contrasting with the truth. It followed on the left posterior fusiform gyrus. Then, Devlin and Gonnerman's computational account used in order to predict the semantic memory models (Merck et al., 2013). Besides cognitive science, the semantic information could be applied in alcohol consumption. It could be designed with the conceptual antecedent of drinking behavior which relates to the cognitive model of substance abuse such as negative feedback and cognition of alcohol use (Austin \& Smith, 2008). However, a similar semantic metric which combined feature could be designed the model through the concept of words, ontology structure and evaluation of the metric. Therefore, the effects of words could be predictability and shared similarity of words. It will occur when giving context which is similar to and related to words (Pirro, 2009) in order to create the actual activities for a solution. Austin and Steele (2001) had designed activities by transferring information, idea and opinion. They developed 
the concept design team member. It led to the map in designing a framework by phase and activity model. It can be captured and analyzed from the various teams to actually design together. Addition to conceptual design phase is consisting of design disciplines, graphic design employs a range of symbolic, material resource. The concept could be patented such as personal, social, technological. Then, data collected by problem solving and activity theory framework (Tan \& Melles, 2010). In this study, we will apply the semantic factors model to illustrate the activity design based on maternal instinct by attention in order to modify alcohol drinking behavior in rural communities. Research Methodology is a qualitative action study.

\section{Methodology}

The model was created and the activities were designed with the knowledge based on alcohol drinking behavior modification, maternal instinct driving, attention and semantic factors designing. This study was applied in San $\mathrm{Pa}$ Tong District. There is located south of Chiang Mai Province, northern of Thailand where the villagers always faced with the effects of high loss on health cost, high statistical drunk-driving and amphetamine problems. The purposive sampling was carried out on thirty housewives being as village health volunteers. However, there were only twenty-six village health volunteers who could participate in this study all the time. They lived in San Pa Tong district. The method of alcohol modification consisted of (1) Analyzing of the problematic classification by attention learning and developing semantic factors model in the previous study and (2) Designing activities the semantic factors model based on maternal instinct implementation. The explanation of the process is described in Figure 1.

\begin{tabular}{|c|c|}
\hline \multicolumn{2}{|c|}{ Research Methodology Designing } \\
\hline 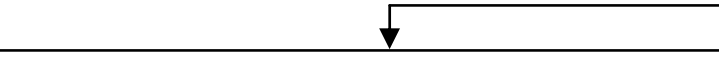 & $\nabla$ \\
\hline $\begin{array}{l}\text { 1. The model creation: Analyzing the problematic } \\
\text { classification in the previous study }\end{array}$ & $\begin{array}{l}\text { 2. The activities designing: Design activities the } \\
\text { semantic factors model based on maternal instinct in } \\
\text { the current study }\end{array}$ \\
\hline$\nabla$ & $\downarrow$ \\
\hline $\begin{array}{l}\text { 1.1. Problematic classification; Maternal instinct } \\
\text { 1.2. Analyzing the creative semantic model; } \\
\text { Attention }\end{array}$ & $\begin{array}{l}\text { 2.1. Analyzing the significant cognition } \\
\text { 2.2. Survey on the feasible conditions in the village } \\
\text { 2.3. Validating the activities by five experts } \\
\text { 2.4. Implementing and evaluating model }\end{array}$ \\
\hline 1.3. Focusing on learning attention; Maternal & \\
\hline $\begin{array}{l}\text { The representation knowledge on alcohol } \\
\text { modification }\end{array}$ & $\begin{array}{l}\text { The activity design using maternal instinct semantic } \\
\text { factors on alcohol drinking behavior modification }\end{array}$ \\
\hline
\end{tabular}

Figure 1. Application of the research methodology design based on maternal instinct semantic factors (Strenberg, 2009)

\subsection{Analyzing of the Problematic Classification}

\subsubsection{Problematic Classification}

Problem justification is identified by stimulating the maternal instinct of housewives as village health volunteers for the alcohol consumption behavior. It is derived from attention love or loving attention which could not drive on alcohol problems in the previous study. The study has to find the way how to drive maternal instinct of housewives in order to lead to the automatic processing of attention. This attention acted as a tool and technique which integrates why-why diagram, the real case study situation and maternal instinct mechanism classification (Ruddick, 1989). This process will be done among the housewives being as village health volunteers. 


\subsubsection{Analyzing the Creative Semantic Model}

The model is made up of semantic memory by searching semantic processing by specific item, semantic code of words by separating neural area and semantic task by associating with differences. The process could be captured by experts who could modify alcohol drinking behavior modification ability in the village. They are housewives acting as village health volunteers who were selected by the village health volunteer leaders. They were selected based on maternal instinct characteristics by their leader agreeableness. HAM (Human association memory) technique was applied to this process: work memory, declarative memory and production memory, and ACT (Adaptive control of thought): a temporal string, a spatial image, and the abstract proposition (Strenberg, 2009). They were used semi-structure in-depth interview, which was validated by the experts. The purpose of this step is to emphasize on attention and representation of semantic factors based on maternal instinct on alcohol drinking behavior modification. The outcome came up with the semantic factors of housewives as village health volunteers. The target group was 18 housewives acting as village health volunteers who were the experts on alcohol drinking behavior modification.

\subsubsection{Maternal Instinct Has to Be Driven, Focusing on Learning Attention}

This step is done to keep to the attention pattern in details. This pattern comprises of cognition, feeling and action tendency. The attention pattern could be analyzed in 7 processes as (1) the problem should be stated and analyzed, (2) the causes of this problem should be asked with "why" question, (3) each cause should be written in the diagram, (4) the question "why" should be asked again and be written in the next column, (5) "why" questions should be asked until reaching no more answers, (6) the causes which are listed in the diagram should be generated for the solutions and (7) the information should be reviewed with evidence of the important cause.

\subsection{Designing Activities and the Semantic Factors Model}

\subsubsection{Analyzing the Semantic Factors Based on Maternal Instinct}

Analyzing the significant cognition and the way to take the goal of alcohol drinking behavior modification from the previous study (Semantic factors based on maternal instinct; housewives as village health volunteers on alcohol drinking behavior modification)

\subsubsection{Designing Activities Based on the Data Collection of Primary Survey}

Doing the survey of the feasible conditions in the village which supported learning process of village health volunteers on semantic factors model based on maternal instinct on alcohol drinking behavior modification. Then, designing activities based on the data collection of primary survey to reach the social capital support such as human resource, the budget, the government, the measurement, etc. and the culture of their community such as religious ceremony, Buddhism faith, etc.

\subsubsection{Validating the Activity Design}

Validating the activities by five experts in each of the activities, matching the context of model and the real situations, sample test in the workshops and improvement the activity design.

\subsubsection{Implementing and Evaluating the Model}

Implementing and evaluating the model of alcohol drinking behavior with the open-questions on the blank papers based on maternal instinct in each of the stations; cognitions, activities, characteristics and others.

\section{Results}

This section will present the strong cognitions and methods based on maternal instinct in order to identify the semantic factors and prove the idea for maternal instinct using. It was used in housewives as village health volunteers as they were working mothers and had the quality of maternal instinct. It was powerful and displayed in attention. In addition, the methods were linked with life skills. The data are presented in Figures 2 and 3. 
Cognition

Method

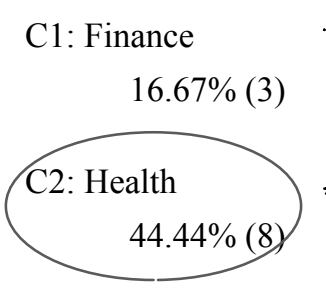

C3: Family

$11.11 \%(2)$

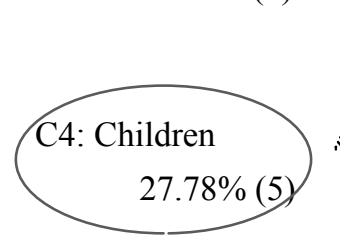

C5: Society's

Recognition

$5.55 \%(1)$

C6: Environment

$5.55 \%(1)$

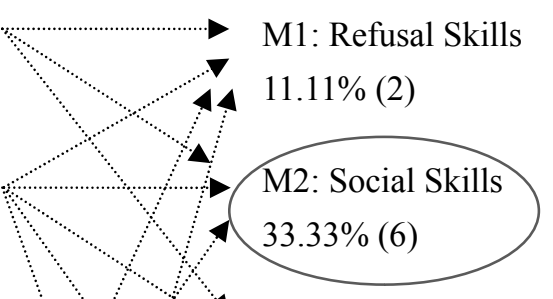

M3: Consciousness (do not kill the time but use the time

beneficial to others)

$5.56 \%(1)$

M4: Being role model in families and communities

$22.22 \%(4)$

M5: Family Communication Skills

$11.11 \%(2)$

M6: Enhancing self-esteem (identify the task that has been done or success)

$5.56 \%(1)$

Figure 2. Analyzing on the semantic factors based on maternal instinct model on alcohol drinking behavior modification

In the previous study, the result showed the imitated semantic factor: housewives' alcohol modification for the rural community. It was designed for the knowledge of village health volunteers who have a high maternal instinct in the community. The semantic factor displayed in attention model consists of cognition, feeling and action tendency. These cognitions are known as finance, health, family, children, society's recognition and environment. They take the feeling and decrease or quit the alcohol drinking behavior of cases. These are the action tendency for method creating. It informs the explicit knowledge in thirteen methods such as (1) sign and symptom monitoring or assessment, (2) describe the effects of alcohol consumption (the most important stimulation), (3) provide concrete example (serve or death case to stimulate the fear of death), etc. Therefore, the current study needs to investigate on the semantic factor model for activity design on alcohol drinking behavior modification by the correlation analysis. The data showed the cognition of experts' perception that stimulates the alcohol consumers. Most cognition was health issues (44.44\%) and children issue (27.78\%). The health cognition related to M1-M4 and M6 (refusal skills, social skills, consciousness, being a role model in families and communities and enhancing self-esteem) and M1-M4 linked to the children's cognition as well as most of the methods were selected in M2 (33.33\%) and M4 (22.22\%). Therefore, the semantic factors model could be derived to the activity design by attention on alcohol drinking behavior. The cognitions should get into the authentic context in rural communities. Feeling of village health volunteers aroused the cognitions from semantic factors knowledge providing from the experts in the community. Finding of this study was the importance of health and children's cognitions, including M1-M4 and M6 which are often used on alcohol drinking behavior modification. The activity design could be represented in Figure 3. They were based on maternal instinct stimulation. They were obtained in the stations designing such as the hospital, the village, the school and the temple as well as used personal resources in their community.

The analysis of the Figures 2 and 3 harmonizes with the attention in maternal instinct concept. The characteristics of maternal instinct relates to the methods of model. It showed some life skills based on attention as were collected the data in order to prove the usability of the model by the frequency percentage of the information analyzing. The data analysis indicated that $\mathrm{C} 2$ (Health cognition) and C4 (Children cognition) were 
more used than the others. Therefore, activity design should emphasize these features in order to stimulate the most of maternal instinct in housewives' village health volunteers. However, this model concerns with the method of alcohol drinking behavior modification by the experts which they succeeded in alcohol modification. The methods are on M2 (Social Skills) and M4 (Being role model in families and communities) to create the structure of the model. As the target group was twenty-six housewives' village health volunteers who have the alcohol drinking behavior in their husbands as well as they have the adolescent in their families. This community activity design is to describe in attention concept. The compound had cognition, feeling and action tendency. It participated in the stakeholder who received the effect of alcohol problems. They were the resources of communities such as health officers, villagers, teachers, monks and alcohol sellers.

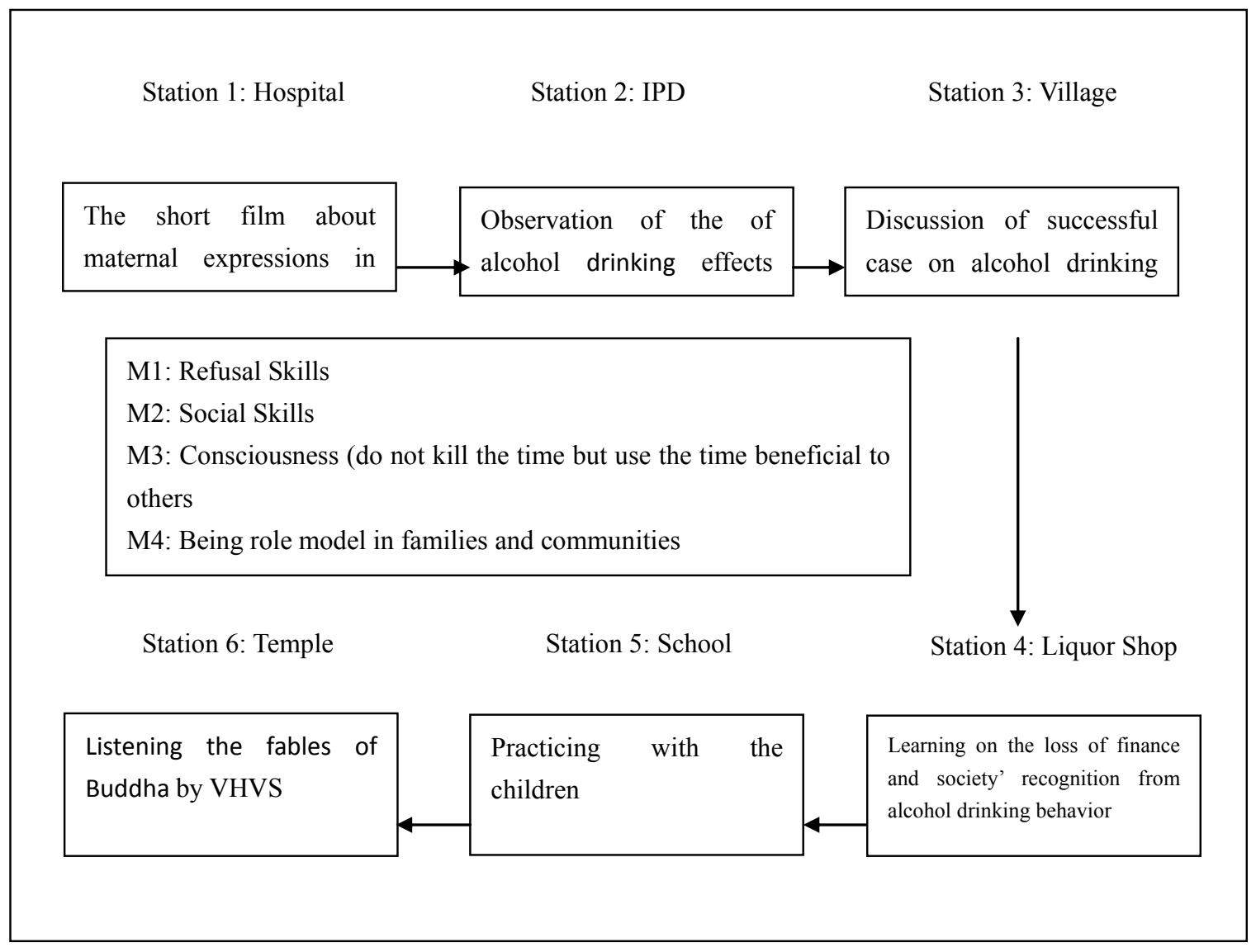

Figure 3. The map of activity design on alcohol drinking behavior modification

The model is described in the six stations. The first station, it started with the activity at the hospital. The subjects should be aroused the interest by the short-film about the real situation of mothers. The media should be selected by the experts to enough stimulate the feeling which affects maternal instinct. The second station, they should observe the role models of the patients who had the effect of alcohol drinking behavior such as cirrhosis of liver, liver cancer and bleeding in the stomach at IPD (In-patient-Department) of the hospital. These images could be illustrated by the sample of health's case study. The third station, as the successful case of a family which had high maternal instinct and ability of alcohol drinking behavior modification in their family and relatives. This station discussed the cognition of health, family and children. The fourth station, learning in the liquor shop was finance, society' recognition and environment. The fifth station, they practiced with the children in schools. Finally, finishing at the temple; were restraint of mental health in the community, including the review and reflect the experience of alcohol on the faith of Buddha. It helped elicit the maternal instinct for their children and husbands through the methods of alcohol drinking behavior (M1-M6).

\section{Findings and Discussion}

\subsection{Findings}

The evaluation of the activity design the semantic factors model based on maternal instinct is usability of the 
model. The maternal instinct affects the relationship of attention; cognition, feeling and action tendency. Besides, the activity design led to life skills: empathy, self-esteem, consciousness and interpersonal relationship. Furthermore, this study found that some characteristics of maternal instinct are significant to the increase of the life skills. It will appear in Tables 1 and 2.

Table 1. Process of maternal instinct semantic factors model

\begin{tabular}{|c|c|c|c|}
\hline Semantic Factors & Process & Maternal Instinct & Life skills \\
\hline 1. Finance & 1. Maternal VDO & 1. Sympathy & \\
\hline $88.46 \%$ & $100 \%$ & $89.73 \%$ & 1. Empathy \\
\hline 2. Health & 2. Illness cases & 2. Altruism & $34.62 \%$ \\
\hline $76.92 \%$ & $65.38 \%$ & $84.62 \%$ & \\
\hline 3. Family & 3. Dead cases & 3. Brotherhood & \\
\hline $76.92 \%$ & $88.46 \%$ & $84.62 \%$ & 2. Self-esteem \\
\hline 4. Children & 4. Liquor shop & 4. Caretaking & $76.92 \%$ \\
\hline $76.92 \%$ & $88.46 \%$ & $76.92 \%$ & \\
\hline 5. Society's Recognition & 5. Good cases & 5. Protection & \\
\hline $96.15 \%$ & $76.92 \%$ & $76.92 \%$ & 3. Conciousness \\
\hline 6. Environment & 6. Children & 6. Cooperation & $76.92 \%$ \\
\hline \multirow[t]{5}{*}{$84.62 \%$} & $76.92 \%$ & $84.62 \%$ & \\
\hline & 7. Maternal Sermon & 7. Harmony & \\
\hline & $92.31 \%$ & $84.62 \%$ & 4. Interpersonal Relationship \\
\hline & & 8. Self-sacrifice & $23.08 \%$ \\
\hline & & $84.62 \%$ & \\
\hline
\end{tabular}

Table 1 represents the relationship of the semantic factors based on maternal instinct by attention to the activity design for usability of the model in order to alcohol drinking behavior modification. Table 1 started with the initial of attention; cognitions and it connected with the process in the station designing. They impacted on maternal instinct characteristics. Besides, the activities were related to some life skills, this study found that most of the elements of the model were about strong effects, even though it focused on the life skills, the result also found the strong impacts which were self-esteem $(76.92 \%)$ and consciousness $(76.92 \%)$. Next, the empathy and interpersonal relationship were about rather a medium effect. The activities of the subjects in the six stations are as follows; Station 1: Watching about maternal instinct driving short-films at the hospital, it was found that maternal instinct VDO affected the sympathy feeling of the housewives. Most of their faces looked sad with the tear in their eyes. Their eyes focused on the screen intently. (The chosen films had the similar content as the mothers' roles in reality as in rural communities). Station 2: Observing illness cases at IPD (In-patient-Department) of the hospital. The data could not show the feeling of maternal instinct relation. This information took health cognition to understand the severity of effects of alcohol drinking behavior in real situations. They perceived suffering of patients and their cousins. Station 3: Learning about dead cases and liquor shop in the village. It influences altruism, brotherhood, cooperation, harmony and self-sacrifice. As they informed the participation of teamwork activities, they studied about society and environment as well as finance discussion. Station 4: Discussing with the role models of alcohol drinking behavior modification in the village. The good cases would transfer and discuss on the discipline and knowledge sharing of alcohol drinking. The ability of alcohol control and modification technique was in their family through semantic factors chart: housewives' alcohol modification. This activity reflected similarity of the feeling in Station 4. Station 5: Practicing courageousness in the student group. They would learn face-to-face with the children. They used step of counseling to consult the children. This act took sympathy, caretaking and protection. It was found that caregiver arousing provided the information and tried to help the children from their suffering. Station 6: Listening to the monk on "Pleiades" as the activity of the maternal instinct sermon in the fable. It had an effect on the similarity of the feeling in Station 5 including the semantic factors, process and the quality of maternal 
instinct. The features of maternal instinct transferred to the property of life skills such as empathy, self-esteem, consciousness and interpersonal relationship. Besides, the relationship of the semantic factors, process, maternal instinct characteristics and life skills are presented in Table 1. This section will focus on the detail as a relation of maternal instinct characteristics and life skills by cross analysis as shown in Table 2 .

Table 2. Cross analysis: maternal instinct and life skills relation

\begin{tabular}{lcccc}
\hline Instinct & $\begin{array}{c}\text { 1. Empathy } \\
\text { (Percentage/No.of } \\
\text { respondants) }\end{array}$ & $\begin{array}{c}\text { 2. Self-esteem } \\
\text { (Percentage/No.of } \\
\text { respondants) }\end{array}$ & $\begin{array}{c}\text { 3. Consciousness } \\
\text { (Percentage/No.of } \\
\text { respondants) }\end{array}$ & $\begin{array}{c}\text { 4. Interpersonal } \\
\text { Relationship } \\
\text { (Percentage/No.of } \\
\text { respondants) }\end{array}$ \\
\hline 1. Sympathy & $7.69 \%(2)$ & $3.85 \%(1)$ & $7.69 \%(2)$ & $3.85 \%(1)$ \\
2. Altruism & $0 \%(0)$ & $0 \%(0)$ & $0 \%(0)$ & $0 \%(0)$ \\
3. Brotherhood & $7.69 \%(2)$ & $11.54 \%(3)$ & $26.92 \%(7)$ & $11.54 \%(3)$ \\
4. Caretaking & $34.62 \%(9)$ & $76.92 \%(20)$ & $76.92 \%(20)$ & $23.08 \%(6)$ \\
5. Protection & $23.08 \%(6)$ & $30.77 \%(8)$ & $30.77 \%(8)$ & $7.69 \%(2)$ \\
6. Cooperation & $0 \%(0)$ & $0 \%(0)$ & $0 \%(0)$ & $0 \%(0)$ \\
7. Harmony & $11.54 \%(3)$ & $7.69 \%(2)$ & $19.23 \%(5)$ & $19.23 \%(5)$ \\
8. Self-sacrifice & $3.85 \%(1)$ & $7.69 \%(2)$ & $7.69 \%(2)$ & $7.69 \%(2)$ \\
\hline
\end{tabular}

The data were analyzed from the white papers about the opinion of village health volunteers. It was found that the quality of maternal instinct related to life skills. Most of maternal instinct was caretaking and protection characteristic. It was motivated by the activity design on semantic factor; housewives' village health volunteers. The information showed more than 3 in 4 of caretaking characteristics and more than 1 in 4 of protection characteristic were connected with self-esteem and consciousness features of life skills. However, if the characteristic of caretaking was varied, the 4 features of life skills would be increased together such as self-esteem, consciousness, empathy and interpersonal relationship (Veneta, 2005). On the other hand, maternal instinct arousing did not show altruism and cooperation involving, it was not related to 4 features of life skills. To summarize, this outcome showed that the health issue was used by experts mostly. The aims were illness and accidental persons group. The next group was children issue. It focused on mothers or fathers who had children of education age. Generally, we could watch advertising media or short-films which arouse the fear from the overall image in television, internet and newspapers, etc. The context was about the accident caused by alcohol drinking behavior, the terror incidents from alcohol consumption and the positive feedback from decreasing or quitting of alcohol drinking. However, the media still promote continuously, alcohol effects increased as well (Anderson et al., 2009). In my opinion, it is the best solution and modernization of the medium, but alcohol drinking behavior is the action tendency. Comparing with this study, it was found that we could arouse the feeling of subjects. It could motivate the sympathy with maternal instinct characteristic. Nevertheless, it influenced less empathy. For example, the events of a car accident on the road which were commented by the surrounding crowd. They felt interested and sympathetic, but they could not mutually understand to help the victims. Sometime, they might have empathy, but it was not enough to assist the better of events. Therefore, the stimulation only began the process. The other process might be designed the identical goal setting. It has the sample for this study. It was outstanding, these activity design leads to caretaking characteristics, self-esteem and consciousness in life skills. It is possible that the design brings the further effective events. Therefore, the activity design is important which the learning could develop the organization continually.

\subsection{Discussion}

These activities are not necessary for highly-educated people. They could learn and play through the model maternal instinct basis. This model should focus on housewives as village health volunteers. They could discuss on the semantic factor of alcohol modification together. However, maternal instinct driving might be linked to other problem-solving. Noticeably, maternal instinct empowerment is applied in several developing countries such as Bangladesh. Professor Yunus (2007) believed in maternal instinct as it is human capital and this study showed the prominence of caretaking characteristic, self-esteem, consciousness in life skills. They could occur 
automatically and accumulated the potential energy. It would act at once when the events stimulate the persons who had maternal instinct. At all events, the trend of alcohol problems is increasing. The people could grow up under belief and social learning in the rural communities. It is the myth for the cycle of learning. Therefore, the new drinkers would be more and more. Nevertheless, the maternal instinct characteristic might be developed in the people. It could be transferred to the closest members by the practice of daily life in their families. Therefore, this activity design should be an interesting alternative for the social problem, particularly drug problems. It gave an advantage to cost less and can improve the potential of learning in health organization later. Since alcohol drinking behavior modification had been broadly studied usually, the alcohol modification is in favor of the AUDIT (Alcohol-Used-Disorder-Identification-Test) measurement (Babor et al., 2001). It is the standard implementation and easy to use. Therefore, many studies should apply the AUDIT to implement in their methods and pleasant results in the case studies of researches. The AUDIT is the best motivation and the clear steps to help the patients who have risk of alcohol drinking behavior. On the other hand, this study must emphasize on the drive of maternal instinct which is the power in human. The action could be at once when it is aroused by the danger in their children. The events happen from the negligence of their mothers on the effect of alcohol drinking behavior. They see alcohol drinking in daily life as common. Therefore, the problem justification of this study is the housewives as village health volunteers could not drive their maternal instinct on alcohol drinking behavior in rural communities. Instead of studying about the motivation on alcohol modification, the previous study was about the semantic factors model for decreasing or quitting alcohol drinking behavior. It led to these activity design and was proved for usability. However, alcohol consumption is the difficulty to quit in the cycle of rural society in Thailand. As the aim of this study, it should fade out from the members of families. Only mothers begin to stimulate by the events, the others would automatically follow. The dominance of the outcome was caretaking characteristics, self-esteem and consciousness in life skills. It is a significant learning improvement for all of the families and communities. This is different from the other studies. The implementation of activity design might not be successful. It was found that the cooperation of the village health volunteer team is very important. They were good at interpersonal relationship, cohesive in the team and participation of the communities. On the other hand, this model might not be practical in the urban communities because most communities were single family and separated living. Therefore, the qualities of village health volunteers might be the strategies to be studied later. At all the events, the theory of social learning is in the right way (Bandura, 2010). It should be not harmful in the social utilization. Social learning consists of attention, retention and reproduction as well as the attention is crucial for learning behavior. However, alcohol drinking behavior is some part of the acquisition. It should be continually promoted as the role models for learning in the communities. Therefore, the critical thinking of this study is truth, knowledge and value for consideration of cause and effect on the logic system as the people should practice to learn with the model under critical thinking.

\section{Summary and Concluding Remarks}

Thailand faces the poverty due to alcohol drinking behavior in rural communities. Even though the health workers in communities had perceived the negative effects of alcohol drinking, they still over drink the beverage. However, the health workers could not be the role models for their families and people on alcohol drinking behavior. Most of the health volunteers were female. It is possible that they could not drive their maternal instinct for a feasible solution. This study proposes the alternative of maternal instinct driving from semantic factors model developed in order to modify the alcohol drinking behavior in rural communities. The study had an opportunity to propose the new activity design from semantic factors housewives as village health volunteers in the previous study in order to prove the usability of the alcohol modification model. It appeared that the six cognitions related to all six stations in rural communities. Additionally, they harmonized with maternal instinct characteristics; sympathy, altruism, brotherhood, caretaking, protection, cooperation, harmony and self-sacrifice. The out-of-expectation of this study was the life skills; empathy, self-esteem, consciousness and interpersonal relationship (Bastin et al., 2005). They led to the development of the human resources and the potential of health volunteers in order to manage the alcohol drinking behavior in rural communities. Wishing that the advantage of this project can be expanded and spent the less on budget, it could promote and select the volunteers based on maternal instinct. It might help increase the potential of health workers in learning. The point of view showed that semantic factors of housewives as village health volunteers on the alcohol modification model using could be taken to activity design. It also stimulates housewives by applying semantic factors within the attention and implement in decreasing alcohol consumption behavior. Even though alcohol drinking behavior still exists in rural communities, Thailand, this measurement might prove the idea that maternal instinct could be driven by semantic factors within attention creating. It is beneficial and effective to this issue. Therefore, it can be applied to the other groups and other problems. Furthermore, this study can expand the idea and new alternative to the rural communities which might face with the same trouble arising from the alcohol drinking behavior. However, 
the limitation of study suits with the market of rural communities. If it is used in the other place such as urban areas, it might study the semantic factors and the context for model creating and activity design in order to prove the solution again.

\section{References}

Anderson, P., de Bruijn, A., Angus, K., Gordon, R., \& Hastings, G. (2009). Impact of Alcohol Advertising and Media Exposure on Adolescent Alcohol Use: A Systematic Review of Longitudinal Studies. Alcohol and Alcoholism, 44(3), 229-243. http://dx.doi.org/10.1093/alcalc/agn115

Austin, J. L., \& Smith, J. E. (2008). Drinking for negative reinforcement: The semantic priming of alcohol concepts. Addictive Behaviors, 33, 1572-1580. http://dx.doi.org/10.1016/j.addbeh.2008.07.016

Austin, S., \& Steele, J. (2001). Mapping the conceptual design activity of interdisciplinary teams. Design studies, 22, 211-232. http://dx.doi.org/10.1016/S0142-694X(00)00026-0

Babor, T. F., Higgins, B. J. C., Saunders, J. B., \& Monteiro, M. G. (2001). AUDIT The Alcohol Use Disorders Identification Test Guidelines for Use in Primary Care (2nd ed.). World Health Organization.

Bandura, A. (2010). Corsini Encyclopedia of Psychology: 30 JAN 2010.

Bastian, V. A., Burns, N. R., \& Netelbeck, T. (2005). Emotional intelligence predicts life skill, but not as well as personality and cognitive abilities. Personality and Individual Differences, 39(6), 1135-1145. http://dx.doi.org/10.1016/j.paid.2005.04.006

Beeba, D. W., Rose, D., \& Amin, R. (2010). Attention, Learning, and Arousal of Experimentally Sleep-restricted Adolescents in a Simulated Classroom. Journal of Adolescent Health, 47(5), 523-525. http://dx.doi.org/10.1016/j.jadohealth.2010.03.005

Buathong, A. (2005). Social, Culture and Alcohol Consumption among Woman Workers. Unpublished Independent Study Title, Chiang Mai University, Thailand.

Duflo, E., \& Urdy, C. (2004). Intrahousehold Resource Allocation in Cote d'Ivoire: Social Norm, Separate Accounts and Consumption Choices. National BUREAU of Economic Research.

Eberl, C., Wiers, R. W., Pawelczack, S., Rinck, M., Becker, E. S., \& Lindenmeyer, J. (2013). Approach bias modification in alcohol dependence: Do clinical effects replicate and for whom does it work best? Developmental Cognitive Neuroscience, 4, 38-51.

Kar, S. B., Pascual, C. A., \& Chickering, K. L. (1999). Empowerment of women for health promotion: A meta analysis. Social Science \& Medicine, 49, 1431-1460. http://dx.doi.org/10.1016/S0277-9536(99)00200-2

Kawachi, I., Kennedy, B. P., Gupta, V., \& Stith, D. P. (1999). Women's status and the health of women and men: A view from the States. Social Science \& Medicine, 48, 21-32. http://dx.doi.org/10.1016/S0277-9536(98)00286-X

Liu, T.-C., Lin, Y.-C., Tsai, M.-J., \& Paas, F. (2012). Split-attention and redundancy effects on mobile learning in $\begin{array}{lllll}\text { physical environments. } & \text { Computer } \& \quad \text { Education, } & 58(1), & \text { 172-180. }\end{array}$ http://dx.doi.org/10.1016/j.compedu.2011.08.007

Merck, C., Jonin, P.-Y., Vichard, H., Boursiquot, S. L. M., Leblay, V., \& Belliard, S. (2013). Relative category-specific preservation in semantic demantia? Evidence from 35 cases. Brain \& Language, 124, 257-267. http://dx.doi.org/10.1016/j.bandl.2013.01.003

Mowbray, O., Krentzman, A. R., Bradley, J. C., Cranford, J. A., Robinson, E. A. R., \& Grogen, K. A. (2013). The effect of drinking goals at treatment entry on longitudinal alcohol use patterns among adults with alcohol $\begin{array}{lllll}\text { dependence. Drug alcohol } & \text { 182-188. }\end{array}$ http://dx.doi.org/10.1016/j.drugalcdep.2013.01.018

Muntaner, C., Solar, O., Vanroelen, C., Martinez, J. M., Vergasa, M., Santana, V., Castedo, A., . . Benach J. (2010). Unemployment, Informal Work, Precarious Employment, Child Labor, Slavery, and Health Inequalities: Pathways and Mechanisms. International Journal of Health Services, 40(2), 281-295. http://dx.doi.org/10.2190/HS.40.2.h

Nair, N., Tripathy, P., Costello, A., \& Prost, A. (2012). Mobilizing women's group for improved maternal and newborn health: Evidence for impact, and challenges for sustainability and scale up. International Journal of Gynecology and Obstetrics, 119, s22-s25. http://dx.doi.org/10.1016/j.ijgo.2012.03.014

Oei, T. P. S., \& Burrow. T. (2000). Alcohol expectancy and drinking refusal self-efficacy: A test of specificity 
theory. Addictive Behaviors, 25(4), 499-507. http://dx.doi.org/10.1016/S0306-4603(99)00044-1

Pirro, G. (2009). A semantic similarity metric combining features and intrinsic information content. Data \& Knowledge Engineering, 68, 1289-1308. http://dx.doi.org/10.1016/j.datak.2009.06.008

Rehm, J., Shield, K. D., Gmel, G., Rehm, M. X., \& Frick, U. (2013). Modeling the impact of alcohol dependence on mortality burden and the effect of available treatment interventions in the European Union. European Neuropsychopharmacology, 23, 89-97. http://dx.doi.org/10.1016/j.euroneuro.2012.08.001

Rostad, B., Schei, B., \& Krokstad, S. (2006). Socioeconomic Factors and Health in Two Generations of Norwegian Women. Gender Medicine, 3(4). http://dx.doi.org/10.1016/S1550-8579(06)80220-2

Ruddick, S. (1989). Maternal Thinking toward a Politics of Peace (1st ed.). Massachsetts: Beacon press.

Smith, L. A., \& Foxcroft, D. R. (2009). The effect of alcohol advertising, marketing and portrayal on drinking behavior in young people systematic review of propective cohort studies. BMC Public Health, 9(1), 51. http://dx.doi.org/10.1186/1471-2458-9-51

Strenberg, R. J. (2009). Cognitive Psychology (5th ed.). USA.

Sumiyoshi, C., Matsui, M., Sumiyoshi, T., Yamashita, I., Sumiyoshi, S., \& Kurachi, M. (2001). Semantic structure in schizophrenia as assessed by the category fluency test: Effect of verbal intelligence and age of onset. Psychiatry Research, 105, 187-199. http://dx.doi.org/10.1016/S0165-1781(01)00345-6

Tan, S., \& Melles, G. (2010). An activity theory focused case study of graphic designers tool-mediated activities during the conceptual design phase. Design Studies, 31(5), 461-478. http://dx.doi.org/10.1016/j.destud.2010.05.002

Thamarangsi, T. (2006). Thailand: alcohol today. Addition, 101(6), 783-787. http://dx.doi.org/10.1111/j.1360-0443.2006.01477.x

Thavorncharoensap, M., Teerawattananon, Y., Yothasamut, J., Lertpitakpong, C., Thitiboonsuwan, K., Neranitpitagkul, P., \& Chaikledkaew, U. (2010). The economic costs of alcohol consumption in Thailand, 2006. BMC Public Health. http://dx.doi.org/10.1186/1471-2458-10-323

Valentine, G., Holloway, S. L., \& Jayyne, M. (2010). Generational patterns of alcohol consumption: Continuity and change. Health \& Place, 16, 916-925. http://dx.doi.org/10.1016/j.healthplace.2010.05.003

Yunus, M., \& Jolis, A. (2007). Banker to the poor: Penguin Group.

\section{Copyrights}

Copyright for this article is retained by the author(s), with first publication rights granted to the journal.

This is an open-access article distributed under the terms and conditions of the Creative Commons Attribution license (http://creativecommons.org/licenses/by/3.0/). 